homoerotismo femenino. La heterogeneidad del corpus seleccionado, su examen y análisis agudos permiten reconsiderar la envergadura de la literatura erótica más reciente, así como su protagonismo en la subjetivación de identidades cuyo correlato real supone, en contemporaneidad, un desequilibrio del sistema heteronormativo y patriarcal. Así, la vindicación llevada a cabo por Díaz Fernández del género erótico $y$, en especial, del homoerotismo, debe interpretarse como un ejercicio de introspección literaria cuyos resultados han de orientarse a reajustar los valores asociados a dicha literatura y a determinadas prácticas sexuales marginadas. La significación de su obra, por lo tanto, subraya el potencial de la literatura para revestir y modelar realidades que a priori se consideran fijas e inamovibles, atravesando así los límites del mero análisis literario para convertirse en un todo un testimonio cultural determinante $y$, sobre todo, indispensable.

\title{
Género y sociedad en el Egipto romano. Una mirada desde las cartas de mujeres
}

Amaia Goñi Zabalegui

Oviedo, Ediciones de la Universidad de Oviedo, Ediciones Trabe, 2018, 360

pp. ISBN: 978-84-16343-77 y 978-84-8053-950-0

Cuando se habla de Egipto, incluso en el mundo académico, la mente se desplaza rápidamente a la civilización del antiguo Egipto y, en segunda instancia, al período ptolemaico. Parece haber dos cortes insalvables que hacen que esto sea así. En primer lugar, la Aegyptíaca de Manetón termina con la segunda dinastía persa, su Dinastía XXXI, momento en el que Alejandro Magno expulsa a los persas de Egipto y se entroniza como rey (332 a.C.). A pesar de la continuidad tanto cultural como religiosa, el mundo académico parece arar una zanja entre ambos períodos. Se detecta, entre los estudios, cierta discontinuidad. Pero la rotura más grande se da con la muerte de Cleopatra VII en el año 30 a.C. Egipto deja de ser un Estado y pasa a ser una provincia romana. Aquí la separación parece ser mucho más profusa, a pesar de que cultural y socialmente sigue habiendo cierta continuidad, también con sus evidentes diferencias, desde las dinastías faraónicas. La mayoría de los emperadores romanos se representaron iconográficamente como reyes egipcios, construyeron templos dedicados a divinidades egipcias e, incluso, utilizaron la escritura jeroglífica para inscribir sus nombres en las tierras nilóticas. No digo que el estudio del Egipto romano esté falto de trabajos académicos, pero sí que es mucho inferior en número a 
los trabajos egiptológicos propiamente dichos y a trabajos de otras provincias romanas. Si de lo que hablamos es de estudios de género, el número de trabajos aún disminuye más, y es todavía menor si, de nuevo, los comparamos con trabajos sobre otras provincias romanas. Así pues, esta obra de Amaia Goñi Zabalegui resulta relevante porque analiza la convergencia de tres culturas: la egipcia antigua, la griega y la romana, y además lo hace en lengua castellana.

Género y sociedad en el Egipto romano constituye la versión revisada de la tesis doctoral defendida por la autora en 2015 en la Universidad de Salamanca. En ella presenta y valora, desde una perspectiva de género, un gran catálogo de cartas privadas (384) escritas sobre papiro por mujeres que abarcan una cronología desde el siglo I a.C. hasta el siglo III d.C. La investigación se basa en el corpus epistolar de Bagnall y Cribiore (2006) y muchas de las cartas aparecen transcritas en griego, lo que posibilita verificar las traducciones presentadas. Goñi Zabalegui no solo ofrece un análisis lingüístico, sino un estudio de las relaciones domésticas, de poder, de la familia y de la sociedad romana en Egipto. El libro consta de cuatro capítulos junto con la introducción y las conclusiones, precedidos de un prólogo a cargo de María José Hidalgo de la Vega, directora de la tesis doctoral. Además de la extensa lista de fuentes y bibliografía utilizada en la obra, se añaden tres anexos de gran utilidad: el corpus documental, los conjuntos de archivos y dosieres, incluyendo árboles genealógicos y, finalmente, algunos mapas. Este volumen ofrece la posibilidad de ver el Egipto romano desde una nueva perspectiva: las fuentes oficiales y muchas de las privadas nos brindan una cosmovisión masculina, utilizada hasta ahora para construir la historia. Pero obras como esta dan voz a las que ya la tuvieron pero que la historiografía ha silenciado hasta ahora, aquellas mujeres que tenían acceso a la escritura directa o indirectamente. Esto nos abre a una nueva visión del mundo antiguo - la cosmovisión femenina-, es decir, a ver el mundo tal y como lo veían las mujeres de la Antigüedad.

El capítulo I, "Las cartas de mujeres y la práctica epistolar en el Egipto romano", nos acerca al género epistolar sobre papiro en el Egipto romano. A continuación, se presenta el corpus de cartas a estudiar, aproximándose a las distintas problemáticas que la autora se ha encontrado al analizar los documentos (emisor no identificable, fragmentación del documento, documentos no publicados, etc.). El segundo capítulo, "La correspondencia y las relaciones sociales: redes de poder y solidaridad dentro y fuera del ámbito familiar”, aborda uno de los grandes temas del libro, la familia. A partir de las misivas estudiadas la autora analiza los roles de género en la unidad familiar y las relaciones de parentesco. Dentro de este capítulo, es de especial interés el estudio de los mecanismos de solidaridad y reciprocidad entre mujeres libres y esclavas en temas como el embarazo o el parto.

El capítulo III, "Los espacios en las cartas de mujeres: permeabilidad, contactos y movilidad geográfica”, analiza los espacios en los que se mueven las protagonistas 
de las cartas. En él no solo pueden verse los movimientos entre los espacios públicos y privados, sino que se recogen distintos testimonios de mujeres que viajaban tanto por el interior como por el exterior del país. La autora se beneficia también de las fuentes arqueológicas, que le permiten ampliar la información aportada por las misivas objeto de estudio. El resultado es romper con el pensamiento tradicional reflejado en la literatura, en el que a la mujer romano-egipcia se la había relegado tan solo a un ámbito doméstico, y demostrar que tenía también un importante papel fuera de este. Finalmente, el capítulo IV, "El rol económico de las mujeres: situación, participación y gestión económica en las cartas privadas", versa sobre las actividades económicas, uno de los temas más recurrentes en las mismas. Un interesante apartado, relacionado, en parte, con el anterior, donde se muestra a mujeres a cargo de la gestión de propiedades y otras actividades económicas.

En definitiva, este libro de Amaia Goñi Zabalegui será una obra de referencia para los estudios del Egipto grecorromano en lengua castellana, no solo por la gran aportación de fuentes textuales, sino también por abrir el camino de los estudios de género en esta disciplina.

D.O.I.: 10.1344/Lectora2020.26.18

MARC ORRIOLS-LLONCH marc.orriols@uab.cat

Universitat Autònoma de Barcelona

\section{Tornar a encantar el món. El feminisme i la política dels comuns}

Silvia Federici

Traducció d'Aurora Ballester

Manresa, Tigre de Paper, 2019, 286 pp. ISBN: 978-84-16855-47-6

El 1917 Max Weber va parlar del "desencant del món”. A grans trets, assenyalava la desaparició de la religiositat a conseqüència de la racionalització produïda per les formes d'organització social derivades, sobretot, del progrés científic i tecnològic. Quasi un segle després, la pensadora Silvia Federici (1942) llançà un repte: tornar a encantar el món. Ho feia en un article que ara clou el seu darrer llibre, Re-enchanting the World: Feminism and the Politics of the Commons (2018), en versió al català d'Aurora Ballester per a Tigre de Paper.

L'edició recull articles publicats entre els noranta i el 2017. Està dividida en dues parts complementàries: la primera ofereix una anàlisi de les noves formes d'encerclament que han succeit els vells tancaments de terres, mentre que la segona aprofundeix en el comú com a realitat present en certes formes d'organització social. Voldria aprofitar aquestes ratlles per mostrar com, sense abandonar la seva aposta per 